\title{
АНАЛИЗ ВЛИЯНИЯ ДЕНЕЖНОЙ МАССЫ М2 И ГОСУДАРСТВЕННЫХ ФИНАНСОВЫХ РАСХОДОВ НА ЭКОНОМИЧЕСКИЙ РОСТ МОНГОЛИИ
}

\begin{abstract}
АНнотАция. В статье выявлены механизм и степень влияния денежной массы и государственных финансовых расходов на экономический рост. Показано, что обычно для поддержания стабильности социально-экономического развития государство в качестве регулятора использует два макроэкономических инструмента - бюджетно-налоговый и денежно-кредитный. Отмечено, что сводный бюджет ныне является основным финансовым планом Монголии, регулирующим потоки денежных ресурсов и фиксирующим не только доходные и расходные части бюджета, но и главные параметры экономического развития страны. Сделан вывод о том, что хотя увеличение объема государственных финансовых расходов может повысить спрос и положительно поддерживать производство на короткий срок, то не сможет способствовать достижению среднесрочного и тем более долгосрочного экономического роста, а приведет только к экономическому росту в краткосрочной перспективе. Денежная масса, наоборот, поддерживает рост реального валового внутреннего продукта и положительно влияет на экономический рост в среднесрочной и долгосрочной перспективе.

кЛючЕВЫЕ словА. Денежная масса; государственные финансовые расходы; экономический рост; валовой внутренний продукт; инфляция.

ИНФОРМАЦИЯ О СТАТЬЕ. Дата поступления 20 января 2016 г.; дата принятия к печати 26 февраля 2016 г.; дата онлайн-размещения 31 мая 2016 г.
\end{abstract}

G. Amarbayasgalan University for the Humanities,

Ulan-Bator, Mongolia

\author{
ANALYSIS OF IMPACT OF M2 MONEY SUPPLY \\ AND GOVERNMENT FINANCIAL EXPENDITURES \\ ON MONGOLIA'S ECONOMIC GROWTH
}

\begin{abstract}
The article reveals the mechanism and the degree of influence of the money supply and government expenditures on economic growth. It shows that generally in order to maintain stability of socio-economic development the government uses as a regulator two macroeconomic instruments - fiscal and monetary policies. It notes that the consolidated budget is now the main financial plan of Mongolia that regulates the flows of financial resources and fixes not only the budget revenue and spending but also the main parameters of the country's economic development. A conclusion is made that although the increase in the volume of government financial expenditure can increase the demand and positively maintain production for a short period, it will not be able to contribute to achieving the medium-term and especially long-term economic growth and only will lead to economic growth in the short-term prospect. The money supply, on the contrary, supports the growth of real GDP and positively effects the economic growth in mid-term and long term prospects.
\end{abstract}

KEYWORDS. Money supply; government financial expenditures; economic growth; Gross Domestic Product; inflation.

ARTICLE INFO. Received January 20, 2016; accepted February 26, 2016; available online May 31, 2016.

(C) Г. Аларбаясгалан, 2016

\section{Baikal Research Journal}


Обычно для поддержания стабильности социально-экономического развития государство в качестве регулятора использует два макроэкономических инструмента - бюджетно-налоговый (фискальная политика) и денежно-кредитный (монетарная политика). В связи с переходом к рыночным отношениям в Монголии перешли $\kappa$ ранее применяемому планированию функций сводного бюджета, который ныне является основным финансовым планом государства, регулирующим потоки денежных ресурсов и фиксирующим не только доходные и расходные части бюджета, но и главные параметры экономического развития страны.

Соответственно, цель настоящего исследования - выявление механизма и степени влияния денежной массы и государственных финансовых расходов на экономический рост.

Различные научные школы по-разному трактуют ту или иную «настройку» денежно-кредитных и финансовых регуляторов и инструментов [1-11]. Классическая школа не придает значения государственному регулированию, считая, что рынок должен саморегулироваться естественными рыночными законами. Кейнсианцы придают большое значение именно государственному регулированию экономики и активной монетарной политике государства.

Монетаризм в качестве основного регулирующего инструмента рассматривает количество денег в обращении. В экономической литературе Монголии и высказываниях политиков часто встречаются разные взгляды по этим концепциям. На наш взгляд, следует на определенный период не снижать значение государственного регулирования и обращать большее внимание активизации бюджетной и денежно-кредитной систем. Всегда необходимо учитывать то обстоятельство, что мероприятия по повышению эффективности государственных финансовых расходов тесно взаимодействуют и плотно взаимосвязаны с такими макроэкономическими параметрами, как процентная ставка, денежная масса, валютный курс и т. д.

Денежная система государства в основном характеризуется структурой денежного обращения, присутствием или отсутствием наличных денег, порядком осуществления безналичных расчетов, в том числе с использованием денежных суррогатов и деривативов; порядком применения во внутреннем денежном обращении иностранных валют, обмена национальной валюты на иностранную и установления валютных курсов; правами и обязанностями (функциями) эмиссионного центра (как правило, центрального банка страны); порядком создания и функциями коммерческих банков и инструментами и методами денежно-кредитной (монетарной) политики. Обычно под инструментами монетарной политики понимаются механизмы, позволяющие правительству и центральному банку влиять на обращение денежной массы в стране.

В Монголии стратегия монетарной политики и главные пути ее реализации находят отражение в ежегодно утверждаемом Великим Государственным Хуралом документе «Основные направления государственной монетарной политики».

Центральный банк Монголии (Монголбанк) с середины 1990-х гг. осуществляет политику, нацеленную на поддержание стоимости национальной валюты и активно воздействующую на количество денег, находящихся в обращении и кредитовании, что в целом имеет антиинфляционную направленность. Несмотря на перечисленные мероприятия, Монголбанк не смог полностью реализовать антиинфляционную политику. На данную ситуацию повлияли такие моменты, как увеличение процентов на ценные бумаги центрального банка вместо роста предложения денежной массы $M 2$ в экономике; мировой экономический кризис 2009 г.; особенности социально-экономического развития Монголии; отсутствие благоприятной почвы для успешной реализации денежной политики.

\section{Baikal Research Journal}


Тенденция денежно-кредитных показателей в Монголии за 2008-2015 гг. (табл. 1) свидетельствует о том, что на конец 2015 г. денежное предложение в экономике $M 2$ составляло 10050,2 млрд тугр. (на 5,5 \% ниже, чем в предыдущем году), а деньги $M 1-1685,4$ млрд тугр. (на 19,5 \% ниже, чем в 2013 г.), хотя деньги $M 2$ за 2008-2014 гг. увеличились в 4,7 раза, а деньги $M 1$ за 2008-2013 гг. - в 3,2 раза. На наш взгляд, снижение денежного предложения только за последние два года (2013-2014) связано с резким снижением темпов роста валового внутреннего продукта (ВВП) в связи с падением цен на сырьевые ресурсы на мировом рынке и тяжелой экономической ситуацией в стране. Этим же можно объяснить тот факт, что остаток некачественных кредитов, который ежегодно плавно снижался примерно на $16,0 \%$ в 2009-2012 гг., за последние 4 года резко возрос в 3 раза при снижении остатка кредитов за 2015 г. на $6,5 \%$.

Общие показатели деженого состояния за 2008-2015 г2., млрд тугр.

\begin{tabular}{|l|r|r|r|r|r|r|r|r|}
\hline \multicolumn{1}{|c|}{ Показатели } & \multicolumn{1}{|c|}{2008} & \multicolumn{1}{|c|}{2009} & \multicolumn{1}{|c|}{2010} & 2011 & 2012 & 2013 & 2014 & 2015 \\
\hline Денежная масса в обороте & 407,2 & 371,8 & 519,7 & 713,4 & 828,5 & 841,4 & 804,7 & 706,7 \\
\hline $\begin{array}{l}\text { В том числе: } \\
\text { Денежная масса вне } \\
\text { банков }\end{array}$ & 328,7 & 285,0 & 388,2 & 517,5 & 603,4 & 582,0 & 499,3 & 458,7 \\
\hline Деньги $M 1$ & 647,3 & 651,3 & 1157,6 & 1741,1 & 1834,9 & 2093,2 & 1816,7 & 1685,4 \\
\hline Деньги $M 2$ & 2270,0 & 2880,0 & 4680,0 & 6412,3 & 7613,7 & 9454,9 & 10635,8 & 10050,2 \\
\hline Резервные деньги & 633,7 & 733,1 & 945,5 & 1659,8 & - & - & - & - \\
\hline Остаток кредитов & 2635,6 & 2655,0 & 3264,8 & 5641,2 & 6941,1 & 10715,6 & 12440,9 & 11633,6 \\
\hline Остаток сбережений & 1191,5 & 1651,3 & 2366,7 & 2554,2 & 3392,2 & 4892,3 & 5372,0 & 5390,0 \\
\hline $\begin{array}{l}\text { Остаток некачествен- } \\
\text { ных кредитов }\end{array}$ & 188,7 & 462,0 & 374,4 & 330,0 & 293,4 & 564,3 & 623,9 & 867,3 \\
\hline
\end{tabular}

Источник: URL : www.mongolbank.mn/macrodb.aspx.

В результате проведенного исследования выяснили, какая из политик (бюджетная или денежная) более позитивно влияет на темп экономического роста и благосостояние общества.Невзирая на то, что эффективность проведенной денежной политики определялась в результате тщательного анализа, тем не менее надеемся, что данная работа в какой-то мере поможет представить общую картину.

В настоящем исследовании использованы данные за 1991-2014 гг. таких зависимых переменных, как реальный ВВП, государственные финансовые расходы $G E$ и денежная масса $M 2$. Информация обрабатывалась поэтапно при помощи программы обработки и анализа статистической информации «EVeiws» следующим образом:

1. Определение стационарности с использованием расширенного теста ДикиФуллера (Augmented DF, ADF-тест).

2. Нахождение числа лагов с использованием теста причинности К. Грейнджера и метода VAR.

3. Оценка зависимых переменных по минимальному квадратному методу (МКМ).

Анализ был проведен по двум направлениям: влияние государственных финансовых расходов на рост ВВП (табл. 2) и влияние роста денежной массы на рост ВВП. Прежде чем приступить к анализу, проверили стационарность переменных и установили, что реальный ВВП - показатель вторых разностей, государственные расходы - первых разностей и денежная масса - вторых разностей.

При оценке реального ВВП в зависимости от реальных государственных финансовых расходов по МКМ нами был использован метод установления разностей 1-го порядка от ВВП. В результате проверки двух показателей по тесту причинности К. Грейнджера с использованием лагов, было установлено, что размер реальных государственных

\section{Baikal Research Journal}

электронный научный журнал Байкальского государственного университета 
финансовых расходов с отставанием во времени при лагах $1 ; 3-5$ стал причиной изменения реального объема ВВП. При этом выяснили, что рост зарплаты и инфляция находятся в прямой зависимости друг от друга (рис.). Ускоренная инфляция наряду с ростом зарплаты приводит к увеличению номинальной ставки процента по кредиту, тем самым к повышению инвестиционных расходов и снижению реального ВВП.

Таблица 2

Исследование влияния государственных финансовых расходов на рост валового внутреннего продукта в 1991-2014 г2. по методу К. Грейнджера

\begin{tabular}{|c|c|c|c|c|}
\hline Лаг & Нулевая гипотеза & $\begin{array}{c}\text { Размер } \\
\text { выборки }\end{array}$ & DF-статистика & Вероятность \\
\hline \multirow[t]{2}{*}{1} & Госрасходы не объясняют причину ВВП & \multirow[t]{2}{*}{23} & 4,51571 & $0,05061^{3}$ \\
\hline & ВВП не объясняет причину госрасходов & & 31,0120 & $5,4 \mathrm{E}-05^{1}$ \\
\hline \multirow[t]{2}{*}{2} & Госрасходы не объясняют причину ВВП & \multirow[t]{2}{*}{22} & 1,66420 & 0,23020 \\
\hline & ВВП не объясняет причину госрасходов & & 8,92387 & $0,00422^{1}$ \\
\hline \multirow[t]{2}{*}{3} & Госрасходы не объясняют причину ВВП & \multirow[t]{2}{*}{21} & 4,75413 & $0,02978^{2}$ \\
\hline & ВВП не объясняет причину госрасходов & & 7,79191 & $0,00716^{1}$ \\
\hline \multirow[t]{2}{*}{4} & Госрасходы не объясняют причину ВВП & \multirow[t]{2}{*}{20} & 3,67712 & $0,07615^{3}$ \\
\hline & ВВП не объясняет причину госрасходов & & 6,69240 & $0,02118^{2}$ \\
\hline \multirow[t]{2}{*}{5} & Госрасходы не объясняют причину ВВП & \multirow[t]{2}{*}{19} & 6,86660 & $0,07183^{3}$ \\
\hline & ВВП не объясняет причину госрасходов & & 2,20416 & 0,27388 \\
\hline
\end{tabular}

Уровень доверия полученных результатов: ${ }^{1}-0,01 \% ;^{2}-0,05 \% ;^{3}-0,1 \%$.

Источник: URL : www.1212.mn.

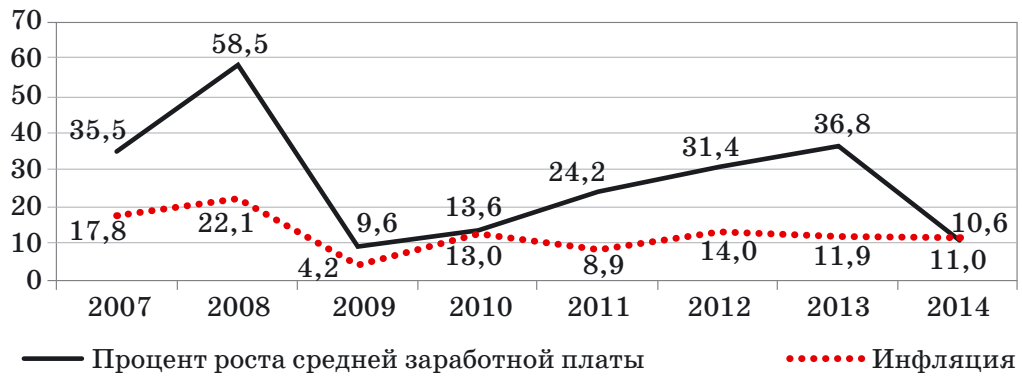

Диналика изменений заработной платы и инфляции в 2007-2014 г2., \%

При проведении оценки влияния расходов на рост ВВП в 1991-2014 гг. с отставанием во времени на 1 лаг методом МКМ использовали следующую формулу:

$$
D(G D P)=0,750 G E-0,568 G E(-1)+e_{t},
$$

где $G D P$ - реальный ВВП; $G E$ - реальные госрасходы; $e_{t}$ - ошибка оценки.

В результате выяснилось, что размер реальных государственных расходов определяет 86,7 \% роста ВВП (табл. 3 ). Причем, если реальные государственные финансовые расходы увеличатся на 1 млн тугр., то реальный ВВП отчетного периода увеличится на 0,75 млн тугр., а за год реальный ВВП снизится на 0,57 млн тугр.

Другими словами, реальные государственные финансовые расходы как бы поддерживают рост спроса, увеличивают производство и ВВП на краткосрочную перпективу, но рост спроса в дальнейшем поощряет и подхлестывает инфляцию:

$$
\begin{gathered}
\text { номинальная ставка процента по кредиту }= \\
=\text { реальная ставка процента по кредиту + инфляиия. }
\end{gathered}
$$

Исходя из чего в долгосрочном плане реальные государственные финансовые расходы оказывают отрицательное влияние на рост реального ВВП.

\section{Baikal Research Journal}


Исследование влияния государственных финансовых расходов на рост валового внутреннего продукта в 1991-2014 22.

\begin{tabular}{|l|r|r|r|r|}
\hline \multicolumn{1}{|c|}{ Показатель } & Коэффициент & Стандартная ошибка & $t$-статистика & Вероятность \\
\hline Реальные госрасходы $G E$ & 0,749739 & 0,102043 & 4,309353 & 0,0005 \\
\hline$G E(-1)$ & $-0,567639$ & 0,109134 & $-3,093809$ & 0,0070 \\
\hline$R$-квадрат & 0,866863 & Средняя зависимая переменная & 91512,71 \\
\hline Скорректированный $R$-квадрат & 0,539791 & $S, D$, зависимая переменная & 128197,6 \\
\hline S.Е. регресс & 86967,56 & Akaike критерия & 25,68890 \\
\hline Сумма квадратов & $1,21 \mathrm{E}+11$ & Schwarz критерия & 25,78783 \\
\hline Log вероятность & $-229,2001$ & Durbin-Watson статистика & 1,396659 \\
\hline
\end{tabular}

Источник: URL : www.1212.mn.

При исследовании влияния денежной массы на рост ВВП мы сможем дать прямую оценку, потому что реальный ВВП и денежная масса по стационарности являются показателями идентичного порядка. При определении отставания во времени переменных по методу VAR результаты показали, что они по всем показателям относятся к 2-му порядку, но здесь мы использовали лаг 1-го порядка (табл. 4).

Исследование влияния денежной массы на рост ВВП в 1991-2014 22. (размер выборки: 21)

\begin{tabular}{|c|r|r|r|r|r|r|}
\hline Лаг & $L$ логарифм & \multicolumn{1}{c|}{$L R$ тест } & $\begin{array}{c}\text { Ошибка } \\
\text { прогнозов }\end{array}$ & $\begin{array}{c}\text { Akaike крите- } \\
\text { рия данных }\end{array}$ & $\begin{array}{c}\text { Scwarz крите- } \\
\text { рия данных }\end{array}$ & $\begin{array}{c}\text { Hannan Quinn } \\
\text { критерия данных }\end{array}$ \\
\hline 0 & $-452,8251$ & $N A$ & $1,68 \mathrm{e}+22$ & 56,85313 & 56,94971 & 56,85808 \\
\hline 1 & $-420,1349$ & 53,12156 & $4,70 \mathrm{e}+20$ & 53,26686 & 53,55658 & 53,28169 \\
\hline 2 & $-403,7707$ & 22,50067 & $1,04 \mathrm{e}+20$ & 51,72134 & 52,20421 & 51,74607 \\
\hline 3 & $-401,4891$ & 2,566799 & 1,40 е +20 & 51,93614 & 52,61216 & 51,97076 \\
\hline
\end{tabular}

При проведении оценки роста реального ВВП в зависимости от денежной массы по МКМ мы получили следующий результат (табл. 5), который находили по формуле

$$
\mathrm{LOG}(G D P)=11,898+0,214 L O G(M 2)+0,116 \operatorname{LOG}(M 2(-1))+(A R(1)=0,640)+e_{t},
$$

где $L O G(G D P)$ - процент изменения роста реального BBП; LOG(M2) - процент изменения денежной массы; $e_{t}$ - ошибка оценки.

Таблица 5

Исследование влияния денежной лассы на рост ВВП в 1993-2014 г2. методом Least Squares (размер выборки: 21)

\begin{tabular}{|l|r|r|r|r|}
\hline \multicolumn{1}{|c|}{ Показатель } & Коэффициент & Стандартная ошибка & $t$-статистика & Вероятность \\
\hline$C$ & 11,89800 & 0,353318 & 33,67508 & 0,0000 \\
\hline LOG (M2) & 0,213568 & 0,040698 & 3,226187 & 0,0073 \\
\hline LOG (M2(-1)) & 0,115824 & 0,035843 & 2,334567 & 0,0378 \\
\hline$A R(1)$ & 0,640423 & 0,125911 & 5,086325 & 0,0003 \\
\hline$R$-квадрат & 0,983238 & Cредняя зависимая переменная & 14,68166 \\
\hline Скорректированный $R$-квадрат & 0,979047 & S.D. зависимая переменная & 0,243431 \\
\hline S.Е. регресс & 0,035237 & Akaike критерия & $-3,641118$ \\
\hline Сумма квадратов & 0,014900 & Schwarz критерия & $-3,447971$ \\
\hline Log вероятность & 33,12895 & $F$-статистика & 234,6283 \\
\hline Durbin-Wатsоn статистика & 2,016250 & Вероятность (F-статистика) & 0,0000 \\
\hline Перевернутый $A R$ корень & 0,64 & & \\
\hline
\end{tabular}

Зависимая переменная: LOG (ВBП).

Источник: URL : www.1212.mn

\section{Baikal Research Journal}


Из результатов тестирования можно было бы сделать вывод о том, что с увеличением денежной массы на $1 \%$ рост реального ВВП отчетного периода увеличивается на $0,21 \%$, а через год составит $0,11 \%$. Отсюда видим, что денежная масса в целом положительно поддерживает рост ВВП. Приведенные вариации ВВП (табл. 6) показывают, что способность денежной массы положительно влиять на рост реального ВВП увеличивается как на краткосрочную и среднесрочную, так и долгосрочную перспективы.

Таблица 6

Разложение валового внутреннего продукта по периодал

\begin{tabular}{|c|c|c|c|}
\hline Период & Стандартная ошибка & ВВП & M2 \\
\hline 1 & 54528,67 & 100,0000 & 0,000000 \\
\hline 2 & 140320,3 & 93,80717 & 6,192832 \\
\hline 3 & 194615,4 & 96,76706 & 3,232938 \\
\hline 4 & 257409,3 & 97,91572 & 2,084281 \\
\hline 5 & 321949,5 & 96,99993 & 3,000066 \\
\hline 6 & 388234,3 & 94,17266 & 5,827341 \\
\hline 7 & 453868,8 & 89,19233 & 10,80767 \\
\hline 8 & 517031,4 & 81,86315 & 18,13685 \\
\hline 9 & 577282,5 & 72,11064 & 27,88936 \\
\hline 10 & 637560,7 & 60,56118 & 39,43882 \\
\hline
\end{tabular}

Источник: URL : www.1212.mn.

Если увеличение государственных расходов на 1 млн тугр. положительно влияет на рост ВВП в 0,75 млн тугр. за данный год, т. е. на краткосрочную перспективу, то наблюдается тенденция, что через год реальный ВВП снизится на 0,57 млн тугр. А как мы видим, при увеличении денежной массы на $1 \%$ рост реального ВВП увеличится на $0,21 \%$ за текущий период, на $0,11 \%$ - через год.

Следовательно, на основании изложенного сделаем вывод о том, что хотя увеличение объема государственных финансовых расходов может повысить спрос и положительно поддерживать производство на короткий срок, то не сможет способствовать достижению среднесрочного и тем более долгосрочного экономического роста, а приведет только к экономическому росту в краткосрочной перспективе. Денежная масса, наоборот, поддерживает рост реального ВВП и положительно влияет на экономический рост в среднесрочной и долгосрочной перспективах.

На наш взгляд, именно поэтому Монголбанк для выполнения стоящих перед ним задач каждый год должен согласовывать с правительством один из важнейших инструментов монетарной политики - рост денежной массы, в результате чего правительство берет на себя ответственность, а центральный банк строго следит за тем, чтобы увеличение обязательств правительства (деньги) не выходили за намеченные пределы, а также правительство должно проводить четкую политику в отношении формирования и использования расходной части государственного бюджета.

В заключение хотелось бы отметить, что еще ни одна страна не нашла методов борьбы с инфляцией, одновременно поддерживая жизненный уровень населения и не сокращая государственных финансовых расходов на социальные программы. Следовательно, постоянное снижение обязательств правительства (денег), в первую очередь, приводит к невозможности нормального ведения хозяйственной деятельности, а это означает сокращение производства, увеличение безработицы и бедности населения. При установлении уровня процентных ставок центральному банку приходится обязательно учитывать прямую взаимосвязь между денежно-кредитной политикой и хозяйственной деятельностью, а также влияние государственной монетарной и фискальной политики на экономический рост в целом.

\section{Baikal Research Journal}




\section{Список использованной литературы}

1. Агапова Т. А. Макроэкономика / Т. А. Агапова, С. Ф. Серегина. - 6-е изд., стереотип. - М. : Дело и Сервис, 2004. - 448 с.

2. Бурлачков В. К. Денежная теория и динамичная экономика: выводы для России / В. К. Бурлачков. - М. : Эдиториал УРСС, 2003. - 352 с.

3. Хэммонд Джил. Практика инфляционного таргетировния : рук. № 29 Центра исследований деятельности центральных банков / Джил Хэммонд. - Лондон : Банк Англии, 2012. $-47 \mathrm{c}$.

4. Кузьмин М. М. Транспарентность денежно-кредитной политики и повышение требований к раскрытию информации Банком России : аналитич. отчет / М. М. Кузьмин, И. Н. Ленков, И. А. Терехова. - М. : Центр экон. исслед. Моск. финан.-пром. акад., 2008. — 29 с.

5. Хартуэлл Кристофер. Независимость центральных банков и глобальный финансовый обвал: взгляд из стран с формирующимся рынком : темат. докл. SIEMS / Кристофер Хартуэлл ; Ин-т исслед. быстроразвивающихся рынков СКОЛКОВО. - M. : Ernst \& Young, 2010. $-48 \mathrm{c}$.

6. Лозгачева Е. Н. Оптимальный консерватизм и независимость Центрального Банка в условиях взаймодействия фиксальной и монетарной политики / Е. Н. Лозгачева, А. В. Дементьев, А. Г. Шульгин. - М. : ГУ ВШЭ, 2007. - 90 с.

7. Трунин В. П. Анализ независимости центральных банков РФ, стран СНГ и Восточной Европы / В. П. Трунин, Д. А. Князев, А. М. Сатдаров. - М. : Ин-т экономики переход. периода, 2010. - 76 с.

8. Фунг Тхе Донг. Роль и место центрального банка в системе денежно-кредитного регулирования на современном этапе / Фунг Тхе Донг // Мир науки. - 2014. - Вып. 4. C. $1-21$.

9. Ахметчина А. В. Независимость центральных банков в системе факторов экономической динамики стран мира / А. В. Ахметчина // Вопросы экономики и права. - 2011. № 1. - С. $53-57$.

10. Моломжамц Д. Финансы, Деньги и Кредит / Д. Моломжамц. - Улаанбаатар, 2008.

11. Анхтуяа Д. E-Views програм ашиглах гарын авлага / Д. Анхтуяа, Ч. Наранчимэг. Улаанбаатар, 2005.

\section{References}

1. Agapova T. A., Seregina S. F. Makroekonomika [Macroeconomics]. 6th ed. Moscow, Delo i Servis, 2004. $448 \mathrm{p}$.

2. Burlachkov V. K. Denezhnaya teoriya i dinamichnaya ekonomika: vyvody dlya Rossii [Monetary theory and dynamic economy: conclusions for Russia]. Moscow, Editorial URSS Publ., 2003. $352 \mathrm{p}$.

3. Khemmond Dzhil. Praktika inflyatsionnogo targetirovniya. Rukovodstvo № 29 Tsentra issledovanii deyatel'nosti tsentral'nykh bankov [Practice of inflation targeting. Guidelines № 29 of Center for Investigating Activities of Central Banks]. London, Bank of England Publ., 2012. $47 \mathrm{p}$.

4. Kuz'min M. M., Lenkov I. N., Terekhova I. A. Transparentnost' denezhno-kreditnoi politiki i povyshenie trebovanii $k$ raskrytiyu informatsii Bankom Rossii [Transparency of monetary policy and increasing demands for revieling information by the Bank of Russia]. Moscow, Center for Economic Research, Moscow State Academy of Business Administration Publ., 2008. 29 p.

5. Khartuell Kristofer. Nezavisimost' tsentral'nykh bankov i global'nyi finansovyi obval: vzglyad iz stran s formiruyushchimsaya rynkom [Independence of central banks and global financial downfall: a look from the countries with shaping markets] Moscow, Ernst \& Young Publ., 2010. $48 \mathrm{p}$.

6. Lozgacheva E. N., Dementyev A. V., Shul'gin A. G. Optimal'nyi konservatizm i nezavisimost' Tsentral'nogo Banka v usloviyakh vzaimodeistviya fiksal'noi i monetarnoi politiki [Optimal conservatism and independence of the Central Bank in terms of cooperation of fiscal and monetary policy]. Moscow, The Higher School of Economics Publ., 2007. 90 p.

7. Trunin V. P., Knyazev D. A., Satdarov A. M. Analiz nezavisimosti tsentral'nykh bankov $R F$, stran SNG i Bostochnoi Evropy [Analysis of independence of central banks of RF, CIS and Eastern Europe countries]. Moscow, Institute for Economy in Transition Publ., 2010. 76 p.

\section{Baikal Research Journal}


8. Fung Tkhe Dong. The role and place of the central bank in the monetary control at the present stage. Mir nauki, 2014, iss. 4, pp. 1-21. (In Russian).

9. Akhmetchina A. V. Independence of central banks in the system of factors of economic dynamics of the countries all over the world. Voprosy ekonomiki i prava = Economic and Law Issues, 2011, no. 1, pp. 53-57. (In Russian).

10. Molomzhamts D. Finansy, Den'gi i Kredit [Finance, Money and Credit]. Ulaanbaatar, 2008.

11. Ankhtuyaa D., Naranchimeg Ch. E-Views program ashiglakh garyn avlaga [Manual for using Eviews]. Ulaanbaatar, 2005.

\section{Информация об авторе}

Аларбаясгалан Голбосурэн - докторант, Институт постградуального образования, Университет гуманитарных наук, 62173, Монголия, г. Арвайхээр, ул. Гэндэн, 205, e-mail: amarg60@yahoo.com.

\section{Author}

Amarbayasgalan Gombosuren - PhD Student, Institute of Post-Graduate Education, University for the Humanities, 205 Genden St., Arvaikheer, 62173, Mongolia; e-mail: amarg60@yahoo.com.

\section{Библиографическое описание статьи}

Амарбаясгалан Г. Анализ влияния денежной массы М2 и государственных финансовых расходов на экономический рост Монголии / Гомбосурэн Амарбаясгалан // Baikal Research Journal. - 2016. - T. 7, № 3. — DOI : 10.17150/2411-6262.2016.7(3).2.

\section{Reference to article}

Amarbayasgalan G. Analysis of impact of M2 money supply and government financial expenditures on Mongolia's economic growth. Baikal Research Journal, 2016, vol. 7, no. 3. DOI : 10.17150/2411-6262.2016.7(3).2. (In Russian).

\section{Baikal Research Journal}

